\title{
Exogenous Oligodendrocyte Progenitor Cell Transplantation Results in Structural and Functional Recovery in a Preterm Infant Cerebral White Matter Injury Rat Model
}

\section{Zhaoyan Wang}

The Sixth Medical Center of PLA General Hospital

\section{Leping Zhang}

The Sixth Medical Center of PLA General Hospital

\section{Yinxiang Yang}

The Sixth Medical Center of PLA General Hospital

\section{Qian Wang}

The Sixth Medical Center of PLA General Hospital

\section{Suqing Qu}

The Sixth Medical Center of PLA General Hospital

\section{Zuo Luan ( $\nabla$ zuoluanek@163.com )}

Sixth Medical Center of PLA General Hospital

\section{Zhixu He}

\section{Guizhou Medical University}

\section{Research}

Keywords: Preterm infant cerebral white matter injury, oligodendrocyte progenitor cells, cell replacement therapy

Posted Date: June 2nd, 2021

DOl: https://doi.org/10.21203/rs.3.rs-533472/v1

License: (c) (i) This work is licensed under a Creative Commons Attribution 4.0 International License. Read Full License 


\section{Abstract}

\section{Background}

Cerebral white matter injury (WMI) is the most common brain injury in preterm infants; it leads to motor and developmental deficits and is often accompanied by cognitive impairment. WMI is characterized by the loss of pre-myelinating oligodendrocytes. Regeneration therapies for preterm neonates with WMI are still in the preclinical phase, among which oligodendrocyte progenitor cell (OPC) transplantation is a promising approach. One promising approach for treating preterm infants is cell replacement therapy, in which lost cells are replaced by human OPCs (hOPCs) derived from human neural stem cells (hNSCs).

Methods

In this study, we developed a method to induce the differentiation of hNSCs into hOPCs. $\mathrm{OLIG}^{+} / \mathrm{NG}^{+} / \mathrm{PDGFRa}^{+} / \mathrm{O}^{+}$hOPCs were enriched and transplanted into the corpus callosum of a preterm infant WMI rat model.

Results

Transplanted hOPCs survived and migrated throughout the major white matter tracts. Morphological differentiation of transplanted hOPCs was observed. Histology and Magnetic resonance imaging (MRI) revealed lesioned structural repair. Electron microscopy revealed the re-myelination of the axons in the corpus callosum. The Morris water maze test revealed a recovery of cognitive function.

\section{Conclusions}

Our study showed that transplantation of hOPCs derived from hNSCs is a viable therapeutic strategy for cerebral WMI. The results of our study contribute to the further development of cell therapeutic strategies.

\section{Background}

Cerebral white matter injury (WMI) is the most common pathological alteration-related brain injury in preterm infants. It is characterized by the loss of white matter [1]. WMI can lead to pediatric neurodevelopmental disorders, resulting in motor and developmental defects accompanied by cognitive deficits. This situation is always persistent from adolescence to adulthood [2]. Clinical evidence indicates that maternal-fetal infection and inflammation are mainly associated with WMI, where hypoxia-ischemia is thought to be the primary cause of neural cell damage [3].

Therapeutic strategies to promote neural regeneration for WMI are still under development. Previous studies have shown that cell transplantation, an approach to transplant neural cells to replenish or replace damaged or dysfunctional tissue, is a promising therapeutic strategy for WMI [4]. Human oligodendrocyte progenitor cells (OPCs; hOPCs) are considered potential candidates for cellular 
transplantation [5]. In the periventricular leukomalacia (PVL) rat model, transplanted hOPCs survived longer than 5 weeks and differentiated into oligodendrocytes expressing myelin basic protein (MBP). Both motor and cognitive recovery were also observed in the rat model [6]. Several studies have shown that transplantation of hOPCs derived from the fetal brain, human induced pluripotent stem cells, or embryonic stem cells leads to myelination in animal models [7-10].

In this study, we established a neonatal rat model of WMI that mirrors the characteristics of WMI in preterm infants [11] to determine whether transplantation of hOPCs to neonatal rats with WMI improves neurobehavioral and cognitive functions as well as neuroprotection.

\section{Methods}

\section{Human neural stem cell (NSC; hNSC) culture}

Aborted human fetuses, aged 7-9 weeks post-conception, were obtained from the Department of Obstetrics and Gynecology of the Sixth Medical Center of PLA General Hospital, Beijing, China, who had requested to terminate gestation and consented to donate the aborted fetus after being fully informed of the study, according to the guidelines approved by the hospital's ethics committee.

hNSCs were isolated from the cortex, ganglionic eminences, and thalamus of human fetuses as previously described [12]. They were amplified in spheres in NSC medium (consisting of a 3:1 mixture of Dulbecco's modified Eagle's medium (DMEM)-F12 medium supplemented with 15 mM N-2hydroxyethylpiperazine-N-ethane-sulphonicacid (HEPES), 0.15\% D-glucose, $100 \mathrm{~g} / \mathrm{mL}$ transferrin, $20 \mathrm{nM}$ progesterone, $60 \mathrm{M}$ putrescine, $30 \mathrm{nM}$ sodium selenite, $5 \mathrm{~g} / \mathrm{mL}$ insulin, $5 \mathrm{~g} / \mathrm{mL}$ heparin, $1 \%$ L-glutamine, $20 \mathrm{ng} / \mathrm{mL}$ basic fibroblast growth factor (bFGF), $20 \mathrm{ng} / \mathrm{mL}$ epidermal growth factor, $10 \mathrm{ng} / \mathrm{mL}$ leukemia inhibitory factor, and $100 \mathrm{U} / \mathrm{mL}$ penicillin and streptomycin). All reagents were purchased from Sigma.

\section{OPC differentiation}

As previously reported, to generate hOPCs, hNSCs were cultured for 10 days to form neurospheres, which were dissociated into single cells and induced to differentiate in differentiation medium (DMEM-F12 medium [3:1] supplemented with $2 \% \mathrm{~B} 27,5 \mathrm{~g} / \mathrm{mL}$ transferrin, $10 \mathrm{nM}$ progesterone, $30 \mathrm{M}$ putrescine, 15 $\mathrm{nM}$ sodium selenite, $5 \mathrm{~g} / \mathrm{mL}$ insulin, $5 \mathrm{~g} / \mathrm{mL}$ heparin, $5 \mathrm{mM}$ lactate, $5 \mathrm{ng} / \mathrm{mL} \mathrm{bFGF}, 10 \mathrm{ng} / \mathrm{mL}$ plateletderived growth factor, $10 \mathrm{ng} / \mathrm{mL}$ neurotrophic factor-3, and $100 \mathrm{U} / \mathrm{mL}$ penicillin and streptomycin). The medium was changed every $2-3$ days [13].

\section{Animal models}

This study was conducted in accordance with the National Institutes of Health Guide for the Care and Use of Laboratory Animals. All protocols were approved by the Clinical Pharmacology Ethics Committee of the Sixth Medical Center of PLA General Hospital, Pediatrics Ethics Committee in Beijing (SCXK20170005). Sprague-Dawley rats (8-9 g) at postnatal day (P) 3 were randomly assigned into three groups ( $\mathrm{n}=9$ in each group): normal control group rats, preterm infant WMI (PWMI) model group 
rats, and graft group rats (model + graft). Hypoxic ischemia $(\mathrm{HI})$ was induced in model rats and graft rats, as previously described [14-16]. Briefly, the pups were cryoanesthetized by incubation on ice for 7 min, the right common carotid artery was severed from the accompanying vagus and sympathetic nerves and permanently ligated using a microelectrocauterizer, and the pups were returned to the dam for $1 \mathrm{~h}$ and then exposed to $6 \% \mathrm{O}_{2}$ for $90 \mathrm{~min}$. Litter-matched sham controls were not subjected to carotid ligation or hypoxia.

\section{Hematoxylin and eosin staining}

Seven days after the induction of $\mathrm{HI}$, three rats were randomly selected from the model group. After anesthetization, the rat brain was perfusion-fixed with $4 \%$ paraformaldehyde. Brain tissue was harvested, fixed, and embedded in paraffin for hematoxylin and eosin staining. Pathologic conditions were observed in the brain dehydrated with gradient ethanol (70\% ethanol for $2 \mathrm{~h}, 80 \%$ ethanol overnight, $90 \%$ ethanol for $2 \mathrm{~h}, 100 \%$ ethanol for $1 \mathrm{~h}$, ), vitrified with xylene, waxed, embedded in paraffin, and conventionally sliced into $5 \mu \mathrm{m}$ tissue sections. Subsequently, the sections were stained with hematoxylin for $10 \mathrm{~min}$, washed with water for $15 \mathrm{~min}$, then stained with eosin for $1 \mathrm{~min}$, and washed with water for $10 \mathrm{~s}$.

\section{OPC transplantation}

Seven days after the induction of HI, OPCs were harvested from the flask and resuspended in phosphate balanced solution (PBS) at a density of $1 \times 10^{5}$ cells $/ \mu \mathrm{L}$, a total of $18 \mu \mathrm{L}$. Then, $3 \mu \mathrm{L}\left(3 \times 10^{5}\right.$ cells) of the suspension was injected into the right corpus callosum of each P9 Sprague-Dawley rat at the following stereotaxic coordinates from bregma: anteroposterior, $-1.0 \mathrm{~mm}$; mediolateral, $1.5 \mathrm{~mm}$; deep level, $-1.5 \mathrm{~mm}$, using a $5 \mathrm{~mL}$ syringe for more than $10 \mathrm{~min}$. The syringe was left in place for an additional $5 \mathrm{~min}$, then gradually withdrawn, and the scalp was sutured and disinfected with $75 \%$ ethanol. The pups were anesthetized with ketamine and xylazine and placed in the stereotactic frame during the surgical procedures. After surgery, pups were placed on heating pads in individual cages until they recovered from anesthesia and returned to their mother until weaning on the $21 \mathrm{st}$ day. At that point, the male and female rats were moved to new cages and raised separately until they were sacrificed. Immunosuppressants were administered to all rats 3 days before surgery, and their administration continued throughout the study. The immunosuppressant cyclosporine (Sandimmun) was administered to all rats intraperitoneally once daily at a concentration of $10 \mathrm{mg} / \mathrm{kg}$, beginning 3 days before surgery.

\section{Immunocytochemistry}

Cells were fixed with $4 \%$ paraformaldehyde (PFA) for 10 min at $25^{\circ} \mathrm{C}$, followed by three washes with PBS, blocked for $1 \mathrm{~h}$ with $3 \%$ bovine serum albumin (Sigma), and permeabilized with $0.3 \%$ Triton $\mathrm{X}-100$ (Calbiochem). Immunolabeled cells were incubated with primary antibodies overnight at $4^{\circ} \mathrm{C}$ and secondary antibodies for $1 \mathrm{~h}$ at $25^{\circ} \mathrm{C}$. Primary antibodies included rabbit anti-OLIG2 (1:200, Millipore, AB9610), mouse anti-NG2 (1:200, Abcam, AB83178), rabbit anti-PDGFR (1:400, Cell Signaling Technology, 5421S), mouse anti-GFAP (1:400, Abcam, ab10062), and mouse anti-04 (1:100, R\&D) and rat anti-MBP (1:100, Abcam). Appropriate Cy3-, Alexa Fluor 594-, and Alexa Fluor 488-conjugated secondary antibodies were used to detect primary antibodies. Goat anti-mouse (1:500, Invitrogen, A-21145), goat anti-mouse 
(1:500, Invitrogen, A-21121), donkey anti-mouse (1:500, Abcam, ab150105), donkey anti-rat (1:200, Abcam, ab150153), rabbit anti-goat (1:500, Abcam, ab150144), or 4,6-diamino-2-phenyl indole (DAPI) was used as the nuclear counterstain.

\section{Immunohistochemistry of tissue sections}

Three months after cell transplantation, after anesthetization, all rats were perfused with $0.1 \mathrm{M}$ PBS and $4 \%$ PFA. The brains were removed, post-fixed in 4\% PFA overnight, and cryoprotected in $30 \%$ sucrose; frozen and coronal brain sections were cut using a Leica CM 1950 cryostat (Leica Microsystems; Leica $\mathrm{CM}, 1850$ ) at a thickness of $14 \mu \mathrm{m}$. The immunostained slides were washed with PBS three times; brain sections were incubated in blocking solution (PBS $+10 \%$ normal goat serum $+0.3 \%$ Triton $\mathrm{X}-100$ ) for $1 \mathrm{~h}$ at $37^{\circ} \mathrm{C}$ and then incubated with a primary antibody diluted in blocking solution overnight at $4^{\circ} \mathrm{C}$. The next day, brain sections were washed three times in PBS, incubated with secondary antibodies (Alexa Fluor 488-, Alexa Fluor 594-, or Cy3-tagged secondary antibodies; 1:500) in PBS for $2 \mathrm{~h}$ at room temperature, and counterstained with DAPI. Pictures were taken under an Olympus DP71 microscope (Olympus Microsystems). The brightness and contrast were optimized using Adobe Photoshop CS5 (Adobe, USA). Goat anti-GFAP (1:500, Abcam, ab53554), rabbit anti-OLIG2 (1:200, Millipore, AB9610), mouse anti-CC1 (Millipore, OP80), rabbit anti-Ki67 (Abcam, ab16667), and human cells were identified using mouse anti-human nuclear antigen (HNA) and clone 235-1 (1:500, Millipore, MAB1281), and MBP was detected with rat anti-MBP (1:100, Abcam, Ab7349). Secondary antibodies conjugated with Alexa Fluor-488 or -594 were used at 1:500 (Invitrogen, Carlsbad, CA, USA; Abcam, Cambridge, MA, USA).

\section{Electron microscopy}

Brains were removed and fixed in 4\% PFA overnight. Then, a piece of corpus callosum tissue near the site of transplantation was resected and fixed in $2 \%$ PFA with $2.5 \%$ glutaraldehyde in sucrose-PBS. Tissue samples were osmicated, dehydrated in ethanol, and embedded in Epon. Ultrathin sectioning was performed using a PowerTome X Ultramicrotome (RMC Products, Boeckeler, Tucson, AZ, USA). The ultrathin sections were collected on formvar-coated copper one-hole grids, contrasted with lead citrate and uranyl acetate, and then examined using a FEIG2 Spirit BioTwin transmission electron microscope (FEl, USA).

\section{Morris water maze test}

The water maze testing took place in a $1.7 \mathrm{~m}$ (diameter) $\times 50 \mathrm{~cm}$ (height) hard black plastic tub that was filled with water $\left(25 \pm 1^{\circ} \mathrm{C}\right)$, with the bottom $45 \mathrm{~cm}$ above ground level. The black platform $(12 \mathrm{~cm}$ diameter $\times 30 \mathrm{~cm}$ height) was submerged $1.5-2.0 \mathrm{~cm}$ below the water surface. The test was performed 3 months after transplantation ( $n=6$ per group). For the navigation trial, rats underwent two trials per day, and there were four different starting points for each trial for a total of 5 days. Rats escaping the platform were restricted to within $60 \mathrm{~s}$ and allowed to rest on the platform for $10 \mathrm{~s}$. The space probe trial, with the platform removed, was conducted on the 6 th day over $60 \mathrm{~s}$. The escape latency, number of platform crossings, percentage of time spent in the platform quadrant, and percent distance traveled in the 
platform quadrant were recorded. Data were analyzed using a tracking program (ZS-001moriss Morris Water Maze Video Analysis System, ZS Dichuang, www.zslab1.com).

Mapping of human cell engraftment -The positions of all anti-human nuclei ${ }^{+}$cells were mapped on 14 $\mu \mathrm{m}$ coronal sections from -5.04 to 2.04 bregma (random selection of a representative case of a graft rat; a total of seven sites and six slices were cut at each site).

Cell counting $-\mathrm{A}$ total of six rats in the graft group (six sections per rat, $14 \mu \mathrm{m}$ coronal section samples of the corpus callosum, from - 3.5 to 1.5 bregma) were examined for cells expressing HNA together with either MBP, GFAP, OLIG2, or Ki67. All data shown represent means \pm standard error of the mean (SEM)

\section{Myelinated axon counts}

Six samples from each group were analyzed using a quantitative evaluation method (G-ratio and ultrastructural grading scores). One hundred myelinated axons from each sample and 600 myelinated axons from each group were calculated. All data shown represent means \pm SD.

\section{Statistics}

Analysis of variance (ANOVA) was performed using GraphPad Prism v5.0c for Macintosh (GraphPad Software, San Diego, CA, USA). Statistical tests for behavioral tasks were performed using one-way ANOVA followed by the Tukey's Honestly Significant Difference (HSD) test with Scheffe's, Bonferroni, and Holm's multiple comparison post-hoc tests. The data met the assumptions of the statistical tests used, and $P$-values less than 0.05 were considered significant.

\section{Results}

\section{Histological analysis of the brains of PWMI model rats}

The PWMI model was established using neonatal rats 3 days after birth because they can simulate the clinical features of PWMI [11]. Brains were harvested 7 days after PWMI was established and were then prepared for analysis. Compared to the control, the brains of PWMI rats were atrophied. The white matter and corpus callosum of PWMI rats were thinner, and abnormal arrangements of neural fibers were observed, indicating net necrosis. In the lesioned area, glial cell karyopyknosis and necrosis were obvious, and the number of glial cells and microglia increased (Figure 1).

MBP is mainly located in the myelin sheath, and its expression can reflect the damage of the white matter. Immunohistochemical staining showed that MBP expression in the corpus callosum and ipsilateral capsula externa was significantly decreased in the hemisphere subjected to a hypoxic-ischemic injury (right hemisphere) compared to the contralateral hemisphere (Figure 2a). Quantitative analysis based on staining area and signal intensity showed a significantly decreased MBP expression in the hemisphere with WMI (Figure 2b and 2c).

\section{In vitro induction of hNSCs to obtain hOPCs}


hNSCs were isolated from the human fetal brain (gestational age, 8-10 weeks) and suspension cultured, allowing neurosphere formation (Figure 3a). We then induced differentiation of hNSCs into hOPCs and detected OPC-specific markers to assess induction efficacy. The morphology of hOPCs derived from hNSCs showed a "bipolar" structure (Figure 3d). As positive staining of OLIG2 represents the efficacy of induction [17], we detected the expression of OLIG2. Besides OLIG2, other OPC-specific markers, including NG2, PDGFR-a, and 04, were detected. Immunofluorescence analysis showed positive staining of NG2/OLIG2/PDGFR-a/O4 (Figure 3b, 3c, 3e, and 3f), indicating the differentiation of hNSCs to hOPCs and, thus, that they were appropriate for cellular transplantation [18].

\section{Survival, migration, and morphological differentiation of transplanted hOPCs in the rat brain}

Transplantation of hOPCs in PWMI rats was conducted via unilateral stereotaxic injection in the right hemisphere corpus callosum, and immunosuppression agents were administered to control the rejection reaction. The brains of PWMI rats were harvested 3 months after transplantation. Because of the relatively high rate of $\mathrm{O}^{+}$cells in our study, we did not purify the induced hOPCs with anti-04 antibodies, as usually done in prior studies before transplantation $[9,19]$.

The brains were further prepared for immunohistochemistry analysis using the human-specific markers stem121 (cytosolic) and anti-human nuclear antigen (hNA). Transplanted hOPCs migrated from the injection site to white matter tracts in the corpus callosum, external capsule, striatopallidal striae, and cortical layer 6 of both hemispheres (Figure 4a-4c). Furthermore, the morphology of engrafted cells developed from bipolar to multipolar shapes, similar to mature oligodendrocytes (Figure 4c). Quantitative analysis showed that the density of $\mathrm{hNA}^{+}$cells in the corpus callosum was $3986 \pm 255 \mathrm{cells} / \mathrm{mm}^{2}$, and the number of $\mathrm{hNA}^{+}$cells decreased in the rostral and caudal regions (Figure $4 \mathrm{~d}$ and $4 \mathrm{e}$ ).

The immunofluorescence assay showed positive expression of OLIG2, CCI, and MBP in the transplanted hOPCs. OLIG2 was expressed in more than $80 \%(81 \pm 2.5 \%)$ of $\mathrm{hNA}^{+}$cells in the corpus callosum (Figure $5 a)$. More than $50 \%(54.9 \pm 8.9 \%)$ of hNA ${ }^{+}$cells expressed CC1 protein (Figure $\left.5 b\right)$, indicating features of immature oligodendrocytes, as previously reported [20]. A few cells expressed MBP (Figure 5e). Furthermore, few transplanted hOPCs differentiated into astrocytes (Figure $5 \mathrm{c}$ ). Cell clusters and overt tumorigenesis were not observed. The proliferation rate of engrafted $\mathrm{hNA}^{+}$cells was less than $7 \%(5.6 \pm$ $0.6 \%$ ) (Figure $5 d$ ), suggesting a low mitotic capacity of transplanted hOPCs.

We further explored whether hOPC transplantation leads to myelination in PWMI rats. Transmission electron microscopy was used to analyze axonal ensheathment and myelin compaction. Compared to axons in normal rats, demyelination and deformed myelin sheaths were observed in most axons of the brains of PWMI rats (Figure 6a Model). In the hOPC transplantation group, demyelination was less common, although most myelin sheaths presented multilayers (Figure 6a Graft). In addition, we compared the G-ratio between different groups. G-ratio was defined as the ratio of axonal diameter to total myelin-ensheathed fiber diameter, and it indicated the severity of myelin sheath damage; the higher 
the score, the worse the myelin injury [21]. The results showed limited damage in the hOPC-transplanted group, as the G-ratio was significantly lower than that in the PWMI group $(P<0.05)$ (Figure 6c-6e).

We also implemented a grading system [22] for the quantitative evaluation of myelin damage (Table 1). A high score indicates damage severity. Consistent with the G-ratio, the scores of the hOPC-transplanted group were significantly lower than those of the PWMI group without hOPC transplantation $(P<0.05)$ (Figure 6b). Taken together, hOPC transplantation led to re-myelination in PWMI rats.

\section{Table 1. Ultrastructural grading scores system}

\begin{tabular}{|lll|}
\hline Category & Grade & Score \\
\hline Normal & 0 & 1 \\
\hline Separation in myelin configuration & 1 & 2 \\
\hline Interruption in myelin configuration & 2 & 3 \\
\hline Honeycomb appearance & 3 & 4 \\
\hline Collapsed myelin forming ovoids & 4 & 5 \\
\hline
\end{tabular}

\section{Effects of hOPCS on spatial learning and memory in PWMI rats.}

To determine whether hOPC transplantation rescues neurobehavioral deficits in PWMI rats, we performed the Morris water maze test to compare spatial learning and memory capabilities between the control, model, and transplantation groups. In the navigation trials, the transplantation group showed a decreased escape latency compared to the model group (Figure 7c). In the probe trials, PWMI rats showed fewer platform crossings, less time spent in the target quadrant, and longer distance to find platforms than the control and graft groups, but there was no significant difference between the control and graft groups (Figure 7a, 7b, and 7d). The results above showed that hOPC transplantation could rescue spatial learning and memory deficits in PWMI rats.

\section{Discussion}

WMI is associated with preterm birth, and hypoxia-ischemia is thought to be one of the underlying pathological causes [23]. PWMI is characterized by the degeneration of pre-oligodendrocytes, leading to a lack of oligodendrocytes [3]. Therefore, supplementation with exogenous hOPCs is a reasonable therapeutic strategy.

The potential of OPC transplantation to restore neural functions was first demonstrated in PVL model rats [24]. Several studies have shown the therapeutic effects of hOPC transplantation in various central nervous system (CNS) injury models, such as leukodystrophies, multiple sclerosis, and PelizaeusMerzbacher disease $[4,6,19,25,26]$. OPC transplantation showed therapeutic potential in a CNS injury animal model, mimicking brain hypoxia-ischemia [16]. 
Evidence of the effects of hOPC transplantation in a PWMI animal model is limited. In the present study, we determined the therapeutic potential of hOPC transplantation in PWMI rats. We found that hOPC transplantation can lead to re-myelination and neurobehavioral recovery. Consistent with previous reports, transplanted hOPCs showed explicit migration ability and differentiation capacity, but the mitotic potential was limited. The Morris water maze test revealed functional recovery following hOPC transplantation in PWMI rats. Exogenous OPC transplantation is always accompanied by a rejection reaction, resulting in the immunity of the host to engrafted cells and even death. We demonstrated that the application of immunosuppressive agents can lower the risk of rejection reactions in exogenous OPC transplantation. Kim et al. [6] showed that after intracerebroventricular transplantation, genetically modified hOPCs survived for more than 5 weeks in vivo and ameliorated neurobehavioral and cognitive deficits in PVL rats, further suggesting that hOPC replacement has the best therapeutic prospects for PWMI. Nevertheless, the technical operations required to obtain hOPCs are relatively complex. We wanted to obtain hOPCs through simple, fast, and efficient methods and intensively study their migration and differentiation trajectories in vivo to explore neuro-repair improvement in ultrastructure and behavior in PWMI.

In clinical trials, the safety and effectiveness of transplanted cells are crucial. First, we presented a reliable strategy that differentiates hOPCs from hNSCs. hOPCs derived using our protocol expressed OLIG2, NG2, PDGFRa, and 04, close to current definitions of oligodendrocyte progenitors [27, 28]. The acquisition of highly enriched OPC preparations allowed us to transplant cells in the absence of isolation, ensuring cell viability and health as much as possible.

In the first 3 days of the model, a large number of inflammatory factors were released, and brain edema did not subside [29,30], which is not conducive for the normal survival of the transplanted cells, and research has shown that transplantation attenuates brain injury at 3-10 days [31, 32]. In the present study, hOPC transplantation was performed 7 days after $\mathrm{HI}$ induction. Based on the injury sites responsible for critical symptoms, hOPCs were injected into the injured lateral corpus callosum using a stereotactic apparatus, and transplantation was performed in situ to achieve accurate repair of the damaged site.

We examined the fate of engrafted hOPCs in the rat corpus callosum after 3 months of transplantation; the cells were effectively implanted, and hOPC populations survived well and were successfully integrated into the host tissue, consistent with the findings of previous studies [26,33]. We found that engrafted hOPCs could greatly migrate, and the trajectory of migration was consistent with the lesions of PWMI.

Transplanted cells develop to have a more mature multipolar morphology. The overwhelming majority of the hOPCs developed into more mature stages and expressed CC1, and a small fraction expressed MBP. Ultrastructural electron microscopy showed a compact myelin sheath that wrapped the axon, while some cells remained in the oligoprogenitor stage and expressed OLIG2, hardly differentiating into astrocytes, which corroborates the results of previous studies $[24,34]$. Less than $7 \%$ of hOPCs within the migratory 
domains were positive for the mitotic marker Ki67 after 3 months, indicating that cells could still differentiate and proliferate. There was no evidence of tumorigenesis or areas of graft overgrowth in implanted hNSC-derived OPCs.

Three months post-transplantation, rats were tested using the Morris water maze to assess behavioral consequences. Consistent with the organizational analysis, PWMI rats showed deficiencies in spatial learning and memory, which were substantially ameliorated by hOPC transplantation. This implies that hOPCs play an important role in white matter recovery, resulting in improved cognitive function.

\section{Conclusions}

Our study clearly showed the key role of hOPCs in white matter recovery and their contribution to the restoration of the cognitive function. Therefore, it is suggested that transplantation of hOPCs restores neurobehavioral disorders as well as cognitive deficits of PWMI animals by preventing neuron demyelination in periventricular white matter. Our findings will further contribute to the improvement of cellular therapeutic strategies.

\section{Abbreviations}

bFGF: basic fibroblast growth factor

CNS: central nervous system

DAPI: 4,6-diamino-2-phenyl indole

DMEM: Dulbecco's modified Eagle's medium

HEPES: N-2-hydroxyethylpiperazine-N-ethane-sulphonicacid

HI: hypoxic ischemia

hNA: human nuclear antigen

hNSCs: human neural stem cells

hOPCs: human oligodendrocyte progenitor cells

HSD: Tukey's Honestly Significant Difference

MBP: myelin basic protein

MRI: magnetic resonance imaging

OPC: oligodendrocyte progenitor cell 
P: postnatal day

PBS: phosphate balanced solution

PFA: paraformaldehyde

PVL: periventricular leukomalacia

PWMI: preterm infant white matter injury

WMI: white matter injury

\section{Declarations}

Ethics approval and consent to participate: All protocols were approved by the Clinical Pharmacology Ethics Committee of the Sixth Medical Center of PLA General Hospital, Pediatrics Ethics Committee in Beijing (SCXK20170005). Informed consent is not applicable.

Consent for publication: Not applicable.

Availability of data and materials: The data that support the findings of this study are available from the corresponding author upon reasonable request.

Competing interests: The authors declare that they have no competing interests.

Funding: This work was supported by the National Key R\&D Program of China (2017YFA0104200). The funding source had no role in the design of the study or collection, analysis, or interpretation of data or in writing the manuscript.

Authors' contributions: ZW and, LZ these authors provided equal contribution to this work. All authors read and approved the final manuscript.

Acknowledgements: Not applicable.

\section{References}

1. Cerisola A, Baltar F, Ferrán C, Turcatti E. Mechanisms of brain injury of the premature baby. Medicina (B Aires). 2019;79:10-4.

2. Back SA. Brain injury in the preterm infant: New horizons for pathogenesis and prevention. Pediatr Neurol. 2015;53:185-92.

3. van Tilborg E, Heijnen CJ, Benders MJ, van Bel F, Fleiss B, Gressens P, et al. Impaired oligodendrocyte maturation in preterm infants: Potential therapeutic targets. Prog Neurobiol. 2016;136:28-49.

4. van der Knaap MS, Wolf NI, Heine VM. Leukodystrophies: Five new things. Neurol Clin Pract. 2016;6:506-14. 
5. Dietz KC, Polanco JJ, Pol SU, Sim FJ. Targeting human oligodendrocyte progenitors for myelin repair. Exp Neurol. 2016;283:489-500.

6. Kim TK, Park D, Ban YH, Cha Y, An ES, Choi J, et al. Improvement by human oligodendrocyte progenitor cells of neurobehavioral disorders in an experimental model of neonatal periventricular leukomalacia. Cell Transplant. 2018;27:1168-77.

7. Windrem MS, Nunes MC, Rashbaum WK, Schwartz TH, Goodman RA, McKhann G, et al. Fetal and adult human oligodendrocyte progenitor cell isolates myelinate the congenitally dysmyelinated brain. Nat Med. 2004;10:93-7.

8. Sim FJ, McClain CR, Schanz SJ, Protack TL, Windrem MS, Goldman SA. CD140a identifies a population of highly myelinogenic, migration-competent and efficiently engrafting human oligodendrocyte progenitor cells. Nat Biotechnol. 2011;29:934-41.

9. Wang S, Bates J, Li X, Schanz S, Chandler-Militello D, Levine C, et al. Human iPSC-derived oligodendrocyte progenitor cells can myelinate and rescue a mouse model of congenital hypomyelination. Cell Stem Cell. 2013;12:252-64.

10. Xu L, Ryu J, Hiel H, Menon A, Aggarwal A, Rha E, et al. Transplantation of human oligodendrocyte progenitor cells in an animal model of diffuse traumatic axonal injury: survival and differentiation. Stem Cell Res Ther. 2015;6:93.

11. Stadlin A, James A, Fiscus R, Wong YF, Rogers M, Haines C. Development of a postnatal 3-day-old rat model of mild hypoxic-ischemic brain injury. Brain Res. 2003;993:101-10.

12. Buchet D, Garcia C, Deboux C, Nait-Oumesmar B, Baron-Van Evercooren A. Human neural progenitors from different foetal forebrain regions remyelinate the adult mouse spinal cord. Brain. 2011;134:1168-83.

13. Wang C, Luan Z, Yang Y, Wang Z, Wang Q, Lu Y, et al. High purity of human oligodendrocyte progenitor cells obtained from neural stem cells: suitable for clinical application. J Neurosci Methods. 2015;240:61-6.

14. Sheldon RA, Chuai J, Ferriero DM. A rat model for hypoxic-ischemic brain damage in very premature infants. Biol Neonate. 1996;69:327-41.

15. Zhu LH, Bai X, Zhang N, Wang SY, Li W, Jiang L. Improvement of human umbilical cord mesenchymal stem cell transplantation on glial cell and behavioral function in a neonatal model of periventricular white matter damage. Brain Res. 2014;1563:13-21.

16. Chen LX, Ma SM, Zhang P, Fan ZC, Xiong M, Cheng GQ, et al. Neuroprotective effects of oligodendrocyte progenitor cell transplantation in premature rat brain following hypoxic-ischemic injury. PLoS One. 2015;10:e0115997.

17. Zhou Q, Choi G, Anderson DJ. The bHLH transcription factor Olig2 promotes oligodendrocyte differentiation in collaboration with Nkx2.2. Neuron. 2001;31:791-807.

18. Goldman SA, Kuypers NJ. How to make an oligodendrocyte. Development. 2015;142: 3983-95

19. Douvaras P, Wang J, Zimmer M, Hanchuk S, O'Bara MA, Sadiq S, et al. Efficient generation of myelinating oligodendrocytes from primary progressive multiple sclerosis patients by induced 
pluripotent stem cells. Stem Cell Reports. 2014;3:250-9.

20. Mohammadi S, Carey D, Dick F, Diedrichsen J, Sereno MI, Reisert M, et al. Whole-brain in-vivo measurements of the axonal g-ratio in a group of 37 healthy volunteers. Front Neurosci. 2015;9:441.

21. Hagiwara A, Hori M, Yokoyama K, Nakazawa M, Ueda R, Horita M, et al. Analysis of white matter damage in patients with multiple sclerosis via a novel in vivo $\mathrm{mr}$ method for measuring myelin, axons, and G-Ratio. AJNR Am J Neuroradiol. 2017;38:1934-40.

22. Aktas S, Comelekoglu U, Yilmaz SN, Yalin S, Arslantas S, Yilmaz BC, et al. Electrophysiological, biochemical and ultrastructural effects of radiotherapy on normal rat sciatic nerve. Int J Radiat Biol. 2013;89:155-61.

23. Follett PL, Deng W, Dai W, Talos DM, Massillon LJ, Rosenberg PA, et al. Glutamate receptor-mediated oligodendrocyte toxicity in periventricular leukomalacia: a protective role for topiramate. J Neurosci. 2004;24:4412-20.

24. Webber DJ, van Blitterswijk M, Chandran S. Neuroprotective effect of oligodendrocyte precursor cell transplantation in a long-term model of periventricular leukomalacia. Am J Pathol. 2009;175:233242.

25. Dooves S, Leferink PS, Krabbenborg S, Breeuwsma N, Bots S, Hillen AEJ, et al. Cell replacement therapy improves pathological hallmarks in a mouse model of leukodystrophy vanishing white matter. Stem Cell Reports. 2019;12:441-50.

26. Marteyn A, Sarrazin N, Yan J, Bachelin C, Deboux C, Santin MD, et al. Modulation of the innate immune response by human neural precursors prevails over oligodendrocyte progenitor remyelination to rescue a severe model of pelizaeus-merzbacher disease. Stem Cells. 2016;34:98496.

27. Alsanie WF, Niclis JC, Petratos S. Human embryonic stem cell-derived oligodendrocytes: protocols and perspectives. Stem Cells Dev. 2013;22:2459-76.

28. Wilson $\mathrm{HC}$, Scolding $\mathrm{NJ}$, Raine CS. Co-expression of PDGF alpha receptor and $\mathrm{NG}_{2}$ by oligodendrocyte precursors in human CNS and multiple sclerosis lesions. J Neuroimmunol. 2006;176:162-73.

29. Al Mamun A, Yu H, Romana S, Liu F. Inflammatory responses are sex specific in chronic hypoxicischemic encephalopathy. Cell Transplant. 2018;27:1328-39.

30. Saliba E, Marret S. Cerebral white matter damage in the preterm infant: pathophysiology and risk factors. Semin Neonatol. 2001;6:121-33.

31. Donega V, van Velthoven $\mathrm{CT}$, Nijboer $\mathrm{CH}$, van Bel F, Kas MJ, Kavelaars A, et al. Intranasal mesenchymal stem cell treatment for neonatal brain damage: long-term cognitive and sensorimotor improvement. PLoS One. 2013;8:e51253.

32. Pimentel-Coelho PM, Magalhães ES, Lopes LM, deAzevedo LC, Santiago MF, Mendez-Otero R. Human cord blood transplantation in a neonatal rat model of hypoxic-ischemic brain damage: functional outcome related to neuroprotection in the striatum. Stem Cells Dev. 2010;19:351-8. 
33. Windrem MS, Schanz SJ, Morrow C, Munir J, Chandler-Militello D, Wang S, et al. A competitive advantage by neonatally engrafted human glial progenitors yields mice whose brains are chimeric for human glia. J Neurosci. 2014;34:16153-61.

34. Windrem MS, Schanz SJ, Guo M, Tian GF, Washco V, Stanwood N, et al. Neonatal chimerization with human glial progenitor cells can both remyelinate and rescue the otherwise lethally hypomyelinated shiverer mouse. Cell Stem Cell. 2008;2:553-65.

\section{Figures}

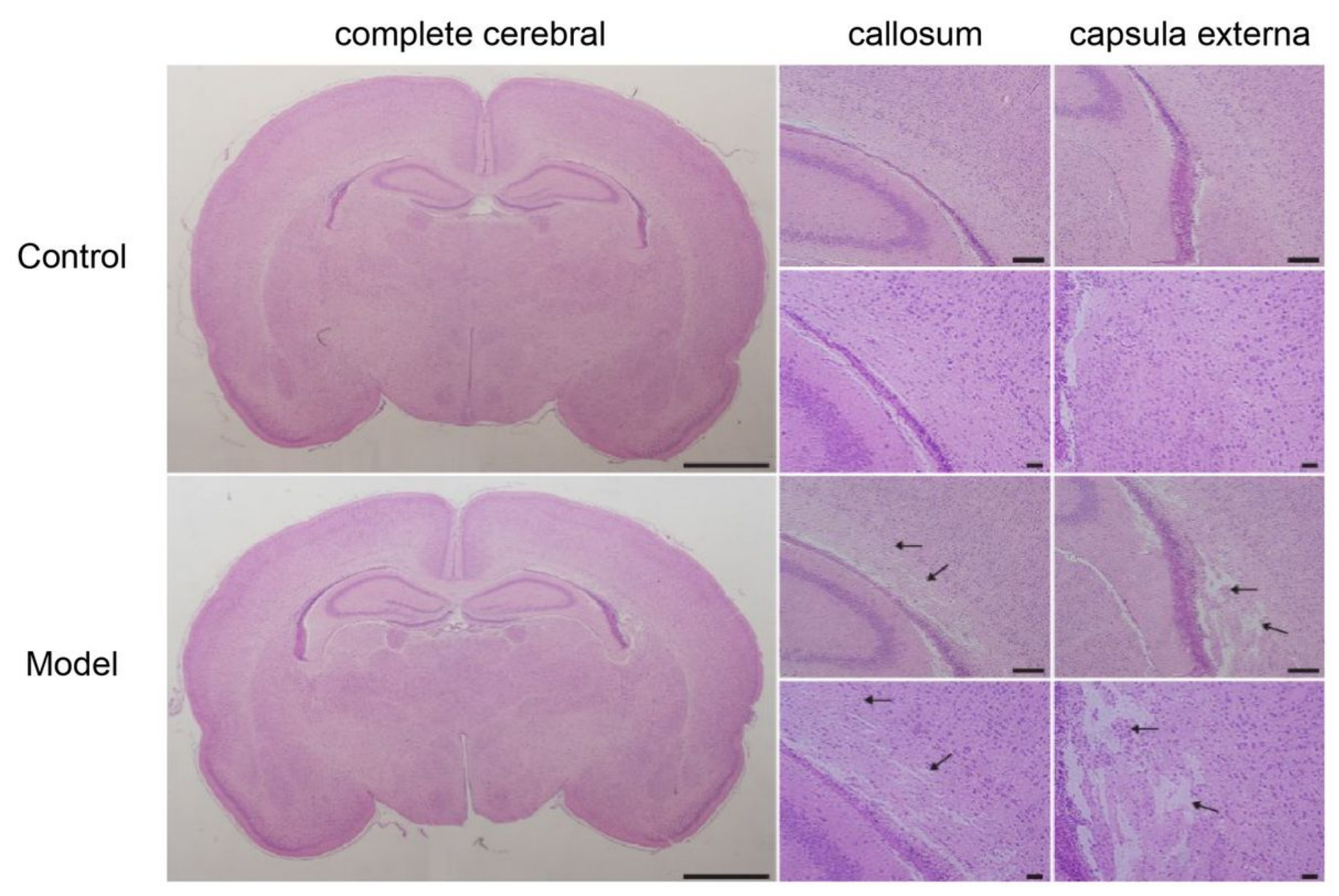

\section{Figure 1}

Hematoxylin and eosin staining. Hematoxylin and eosin staining revealed different injury patterns. The control group was normal, and the model group showed selective white matter injury, especially in the callosum and capsula externa, as indicated by arrows. The scale bars represent $200 \mu \mathrm{m}$. 

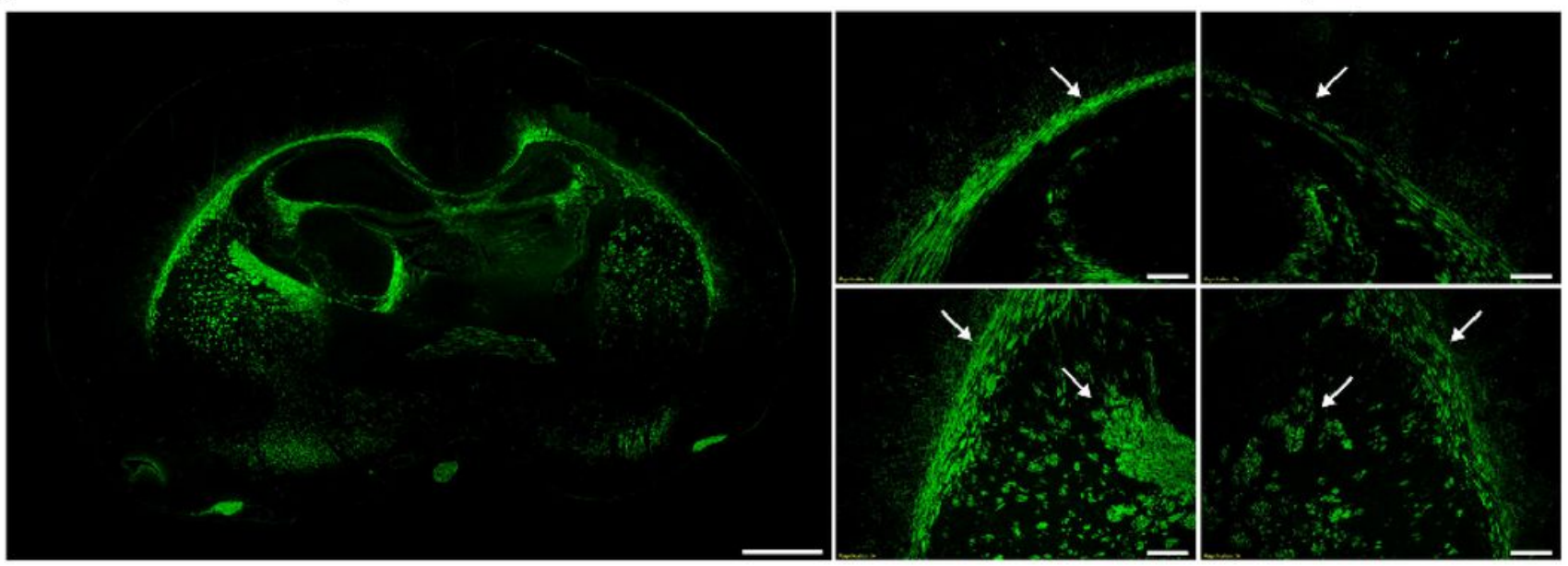

Callosum

B

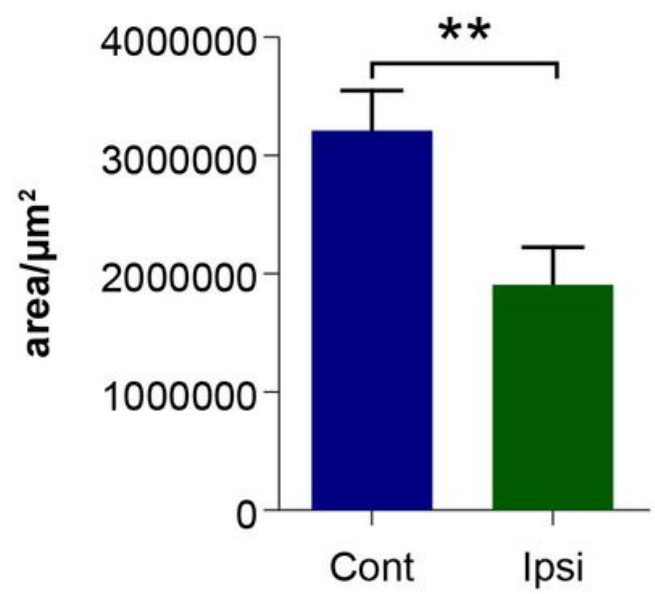

C

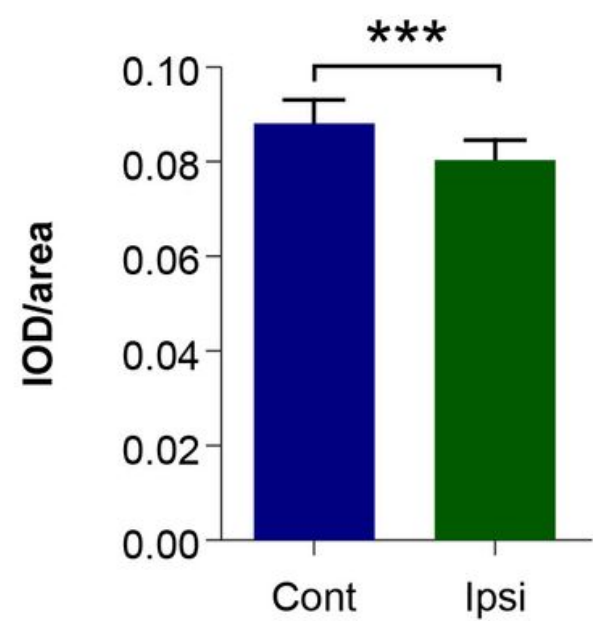

\section{Figure 2}

MBP immunofluorescence staining of the brains of model rats. (A) Immunohistochemistry of MBP showed myelin loss ipsilateral to the severed side in rats. Scale bars, $200 \mu \mathrm{m}$. (B) Immunofluorescence analysis of MBP on both sides of the brain of PWMI rats; MBP immunofluorescence area of contralateral and ipsilateral hypoxic-ischemic injury. ( ${ }^{\star} \mathrm{P}<0.01$, Student's t-test). (C) Immunofluorescence optical density (IOD)/area of contralateral and ipsilateral hypoxic-ischemic injury ( ${ }^{\star \star *} \mathrm{P}<0.001$ by Student's ttest). 

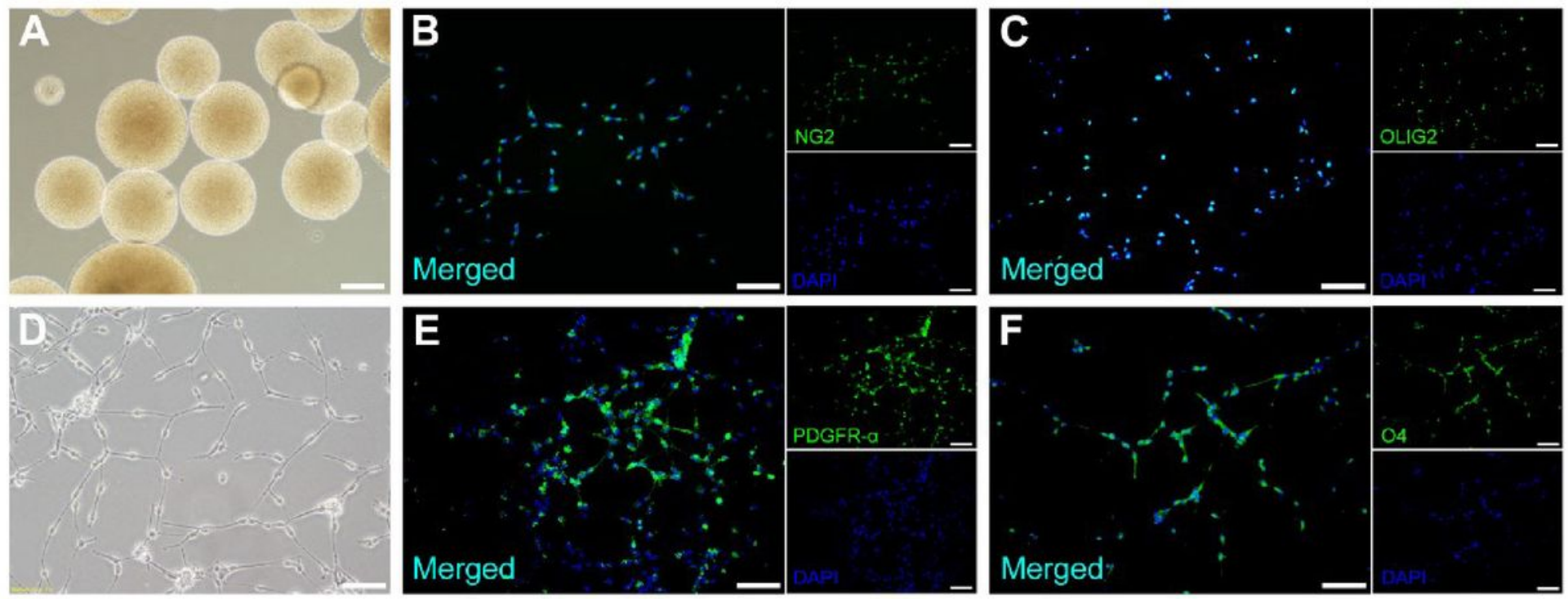

\section{Figure 3}

HNSCs can be differentiated into OPCs. (A) Human neurospheres before differentiation. (B) NG2区 OPCs derived from hNSC differentiation. (C) OPCs differentiated from hNSCs could be identified as OLIG2+. (D) Bipolar cell morphology of OPCs differentiated from hNSCs. (E) OPCs differentiated from hNSCs could be identified as PDGFR-a+. (F) HNSC differentiation into 04+ OPCs. Scale bars: A-F, $100 \mu \mathrm{m}$. 


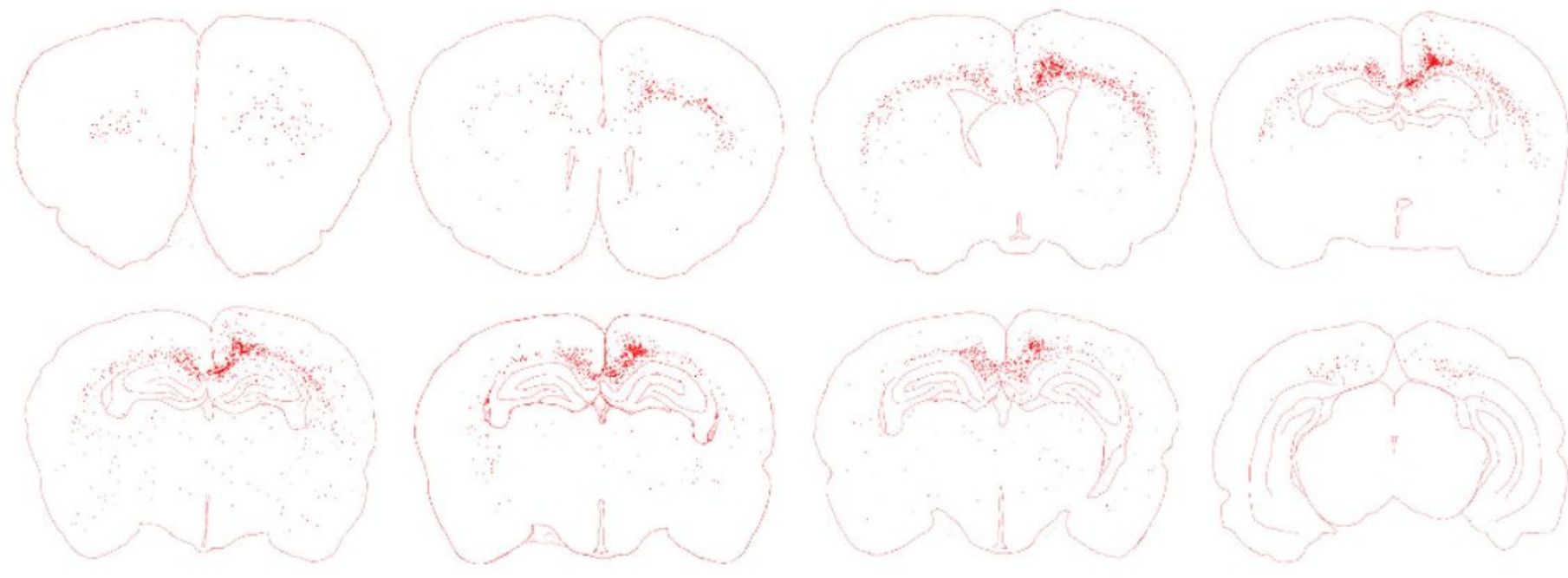

B
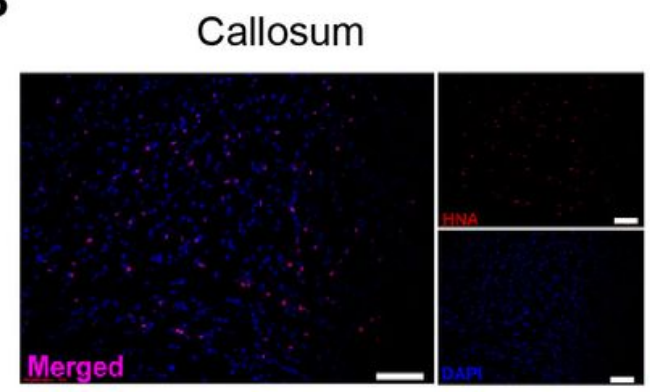

C

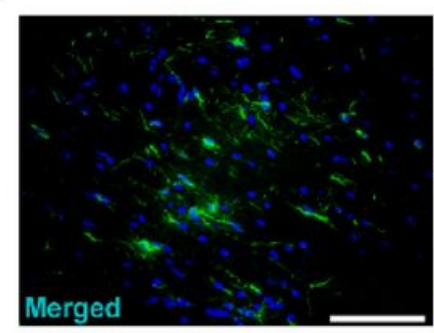

Capsula externa

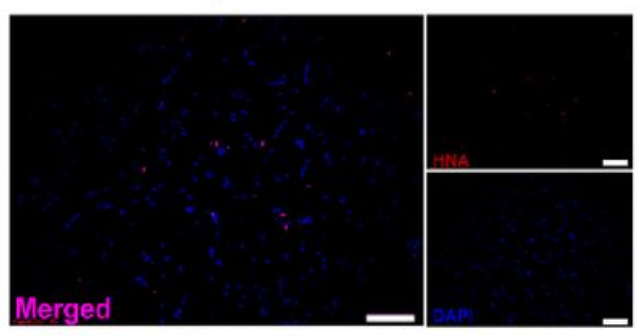

Merged
D

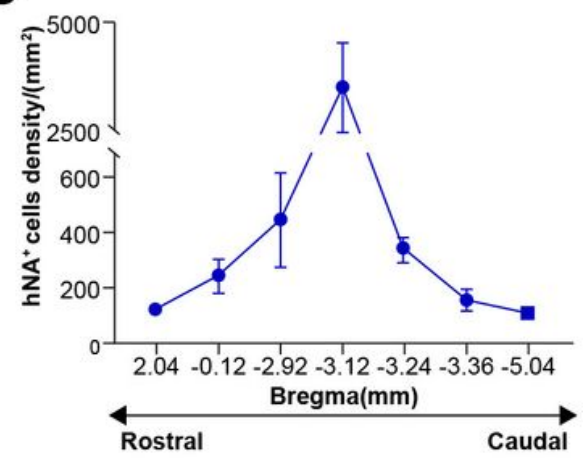

E

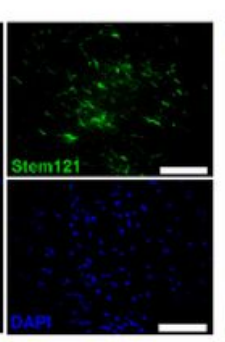

Merged
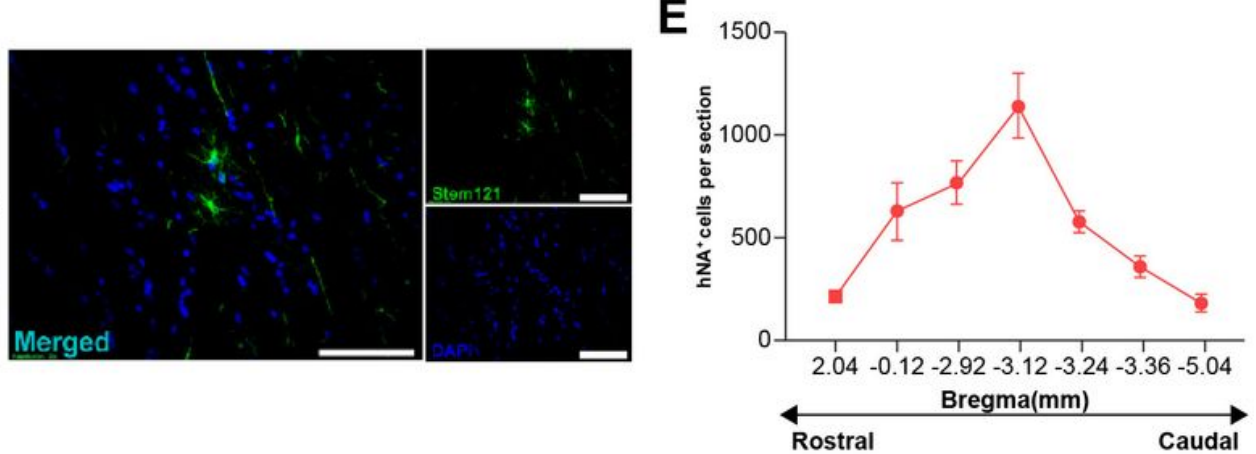

\section{Figure 4}

HOPCs survived, migrated widely, and differentiated into multipolar cell morphology after three months of transplantation. (A) Whole-brain migration map of hOPC transplant-derived cells from a representative case of a graft rat (marked by human nuclear antigen, HNA). (B) Corpus callosum and capsula externa HNA immunofluorescence staining. (C) Corpus callosum and capsula externa 121 immunofluorescence staining. (D) Human cell migration density of the corpus callosum in the rostral-caudal region (marked by human nuclear antigen, HNA). (E) Number of hNA囚 cells per brain slice in the rostral-caudal. Scale bars: BC, $100 \mu \mathrm{m}$. 

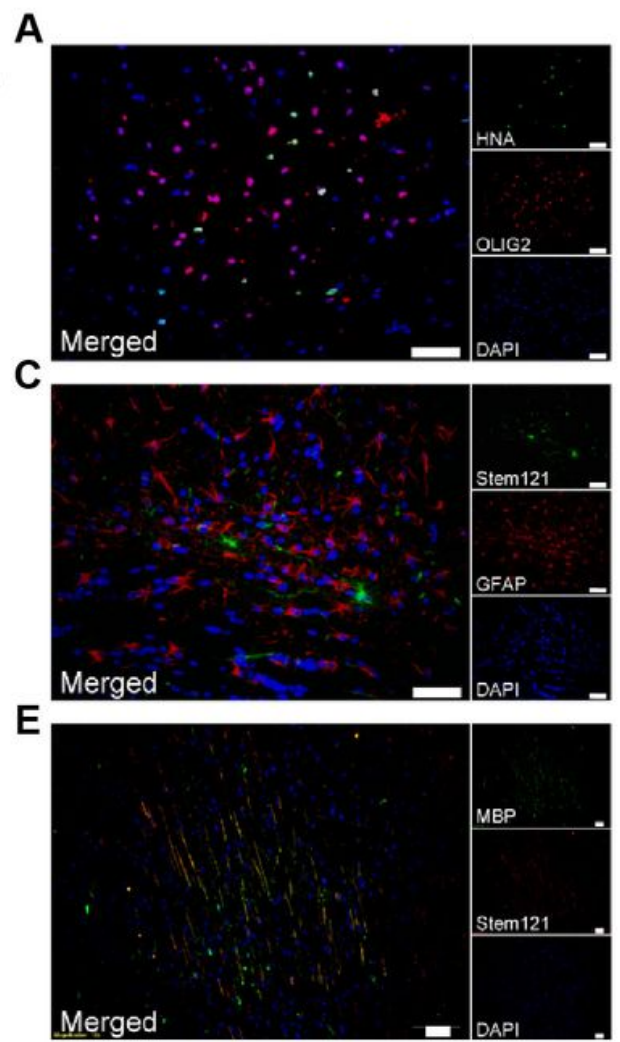

B
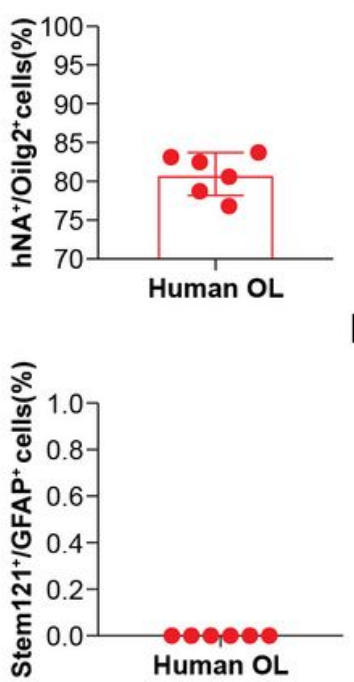

D
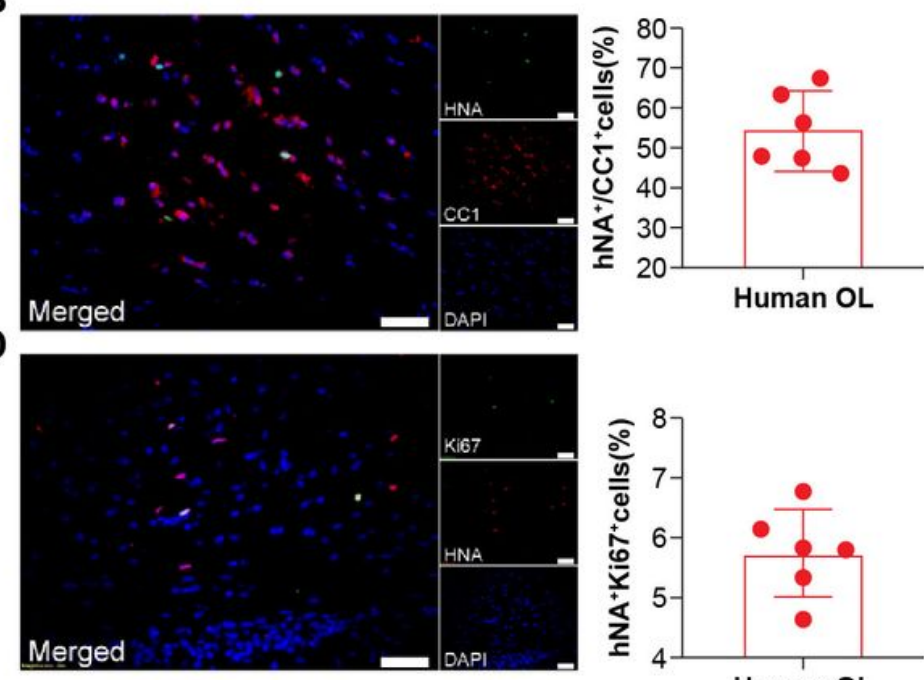

Human OL

\section{Figure 5}

HOPC integration into animals and myelination after three months of transplantation. (A) Immunohistochemistry pictures of the human-specific antibody (HNA, green) and oligodendrocytes restricted progenitors (OLIG2, red) and stereological calculation of the number of HNA $/$ OLIG2】 cells compared to total hNA+ cells ( $\mathrm{n}=6$ animals). (B) Immunohistochemistry pictures of immature oligodendrocytes (CC1, red) and hNAD cells (green) in the brains of model rats. Human CC1+/HNA+ oligodendrocytes were counted and compared with total hNA+ cells ( $n=6$ animals). (C) Immunohistochemistry pictures of the human-specific antibody (Stem121, green) and astrocytes (GFAP, red), and percentage histogram of double-positive cells ( $n=6$ animals). (D) Immunohistochemistry pictures of HNA (red) and cell proliferation (Ki67, green), and percentage histogram of double-positive cells ( $n=6$ animals). (E) Immunohistochemistry pictures of Stem121 (red) and mature oligodendrocytes (MBP, green) ( $n=6$ animals). Scale bar: $A-E, 50 \mu m$. 
A

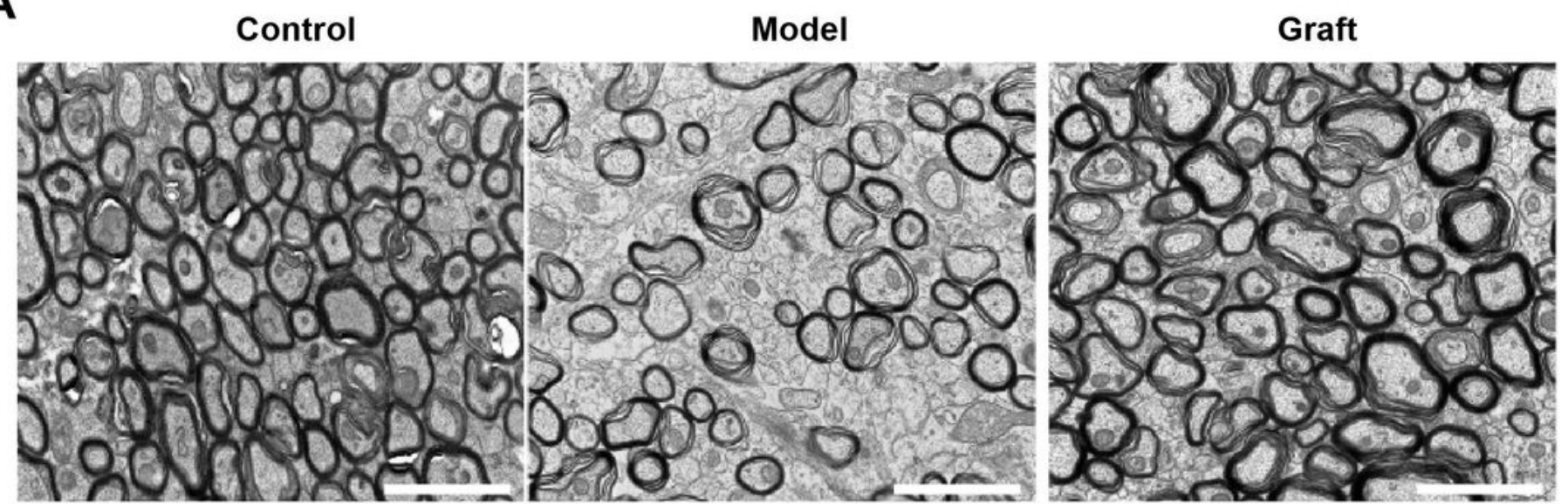

B

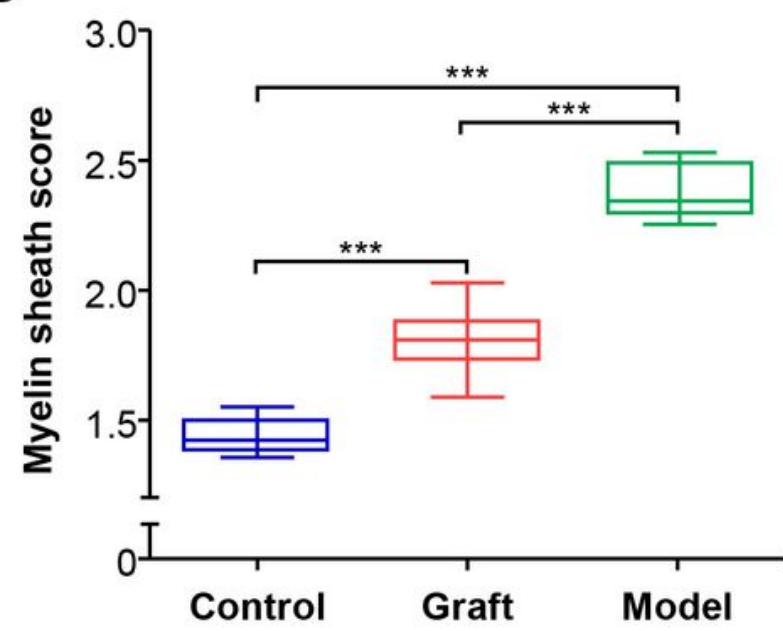

D

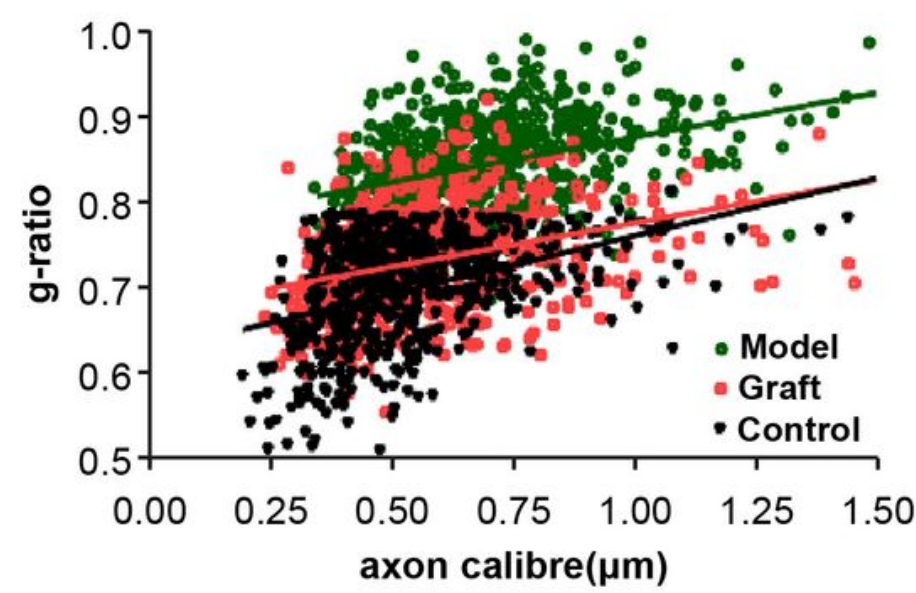

C

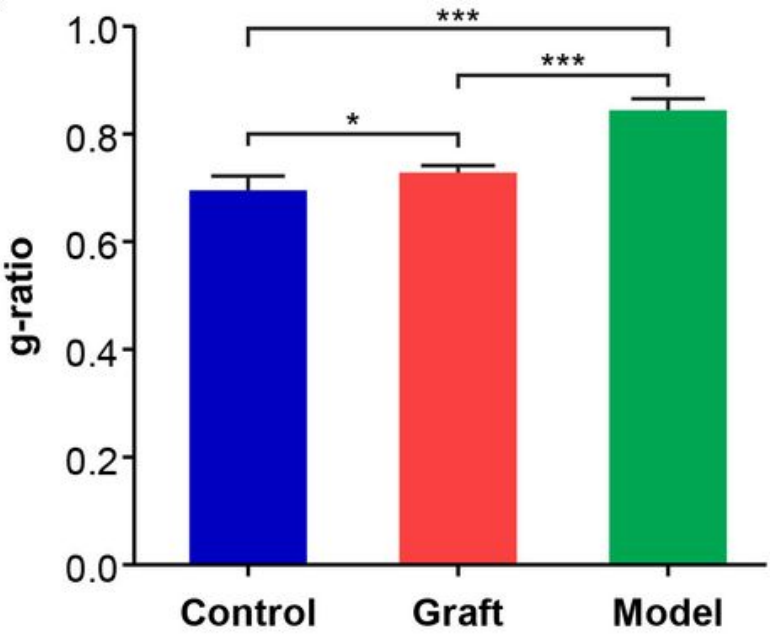

E

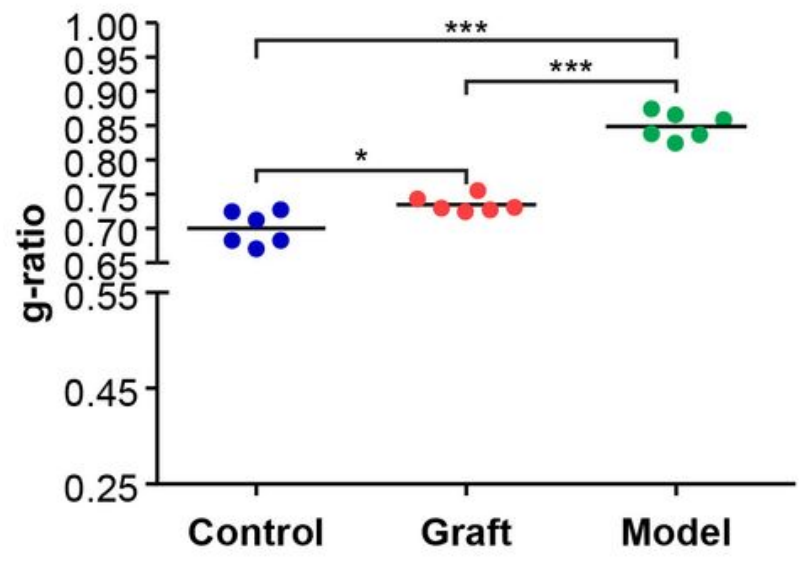

Figure 6

The effects of transplanted OPCs on myelin ultrastructure. (A) Transmission electron micrographs showing a portion of the corpus callosum from the animals in control, model, and graft groups. (B) Mean sheath score of the three groups ( $n=6$ rats per group). ${ }^{\star \star \star} P<0.001$. (C) Mean G-ratio of the three groups ( $n=6$ rats per group). One-way ANOVA test. ${ }^{*} P<0.05, \star \star \star P<0.001$. (D) A scatter plot graph showing the relationship between $\mathrm{G}$-ratio values and axon diameters in the three groups ( $\mathrm{n}=6$ rats per group). (E) A 
plot graph of the three groups showing the mean G-ratio distribution. One-way ANOVA test. *P $<0.05$, $* \star \star P$ $<0.001$.

\section{A}

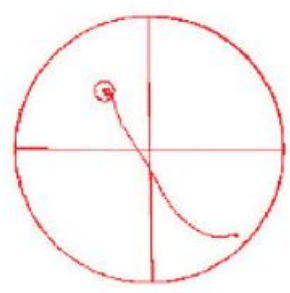

Control

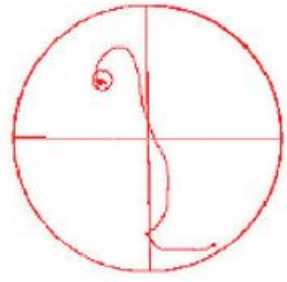

Graft

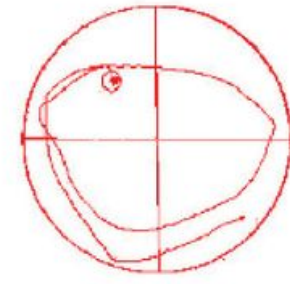

Model
C

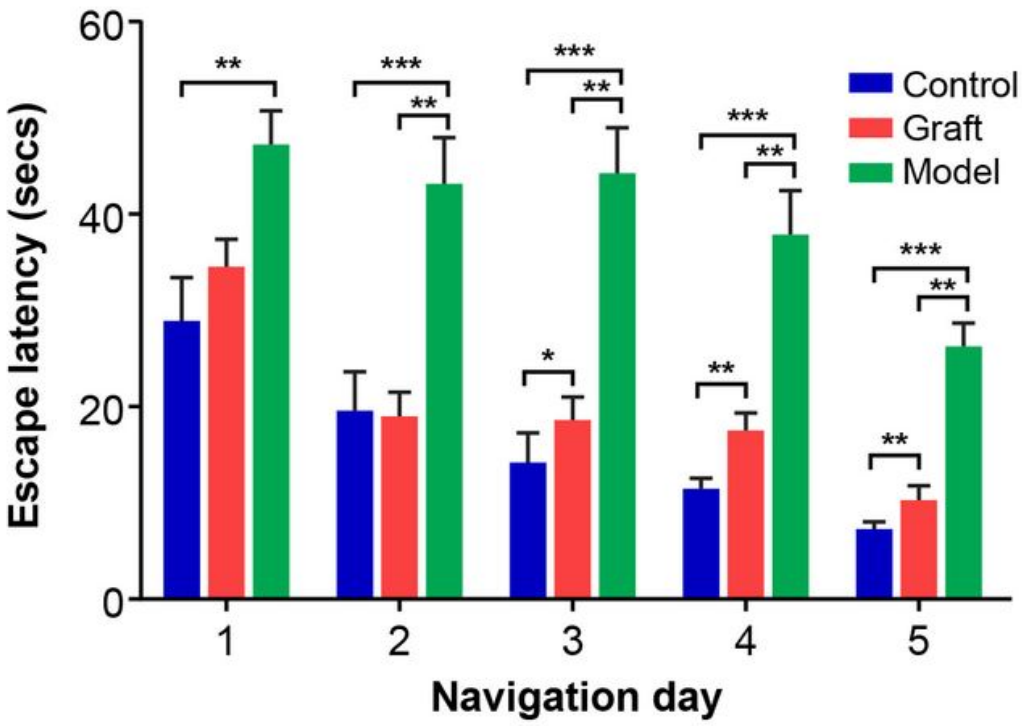

B

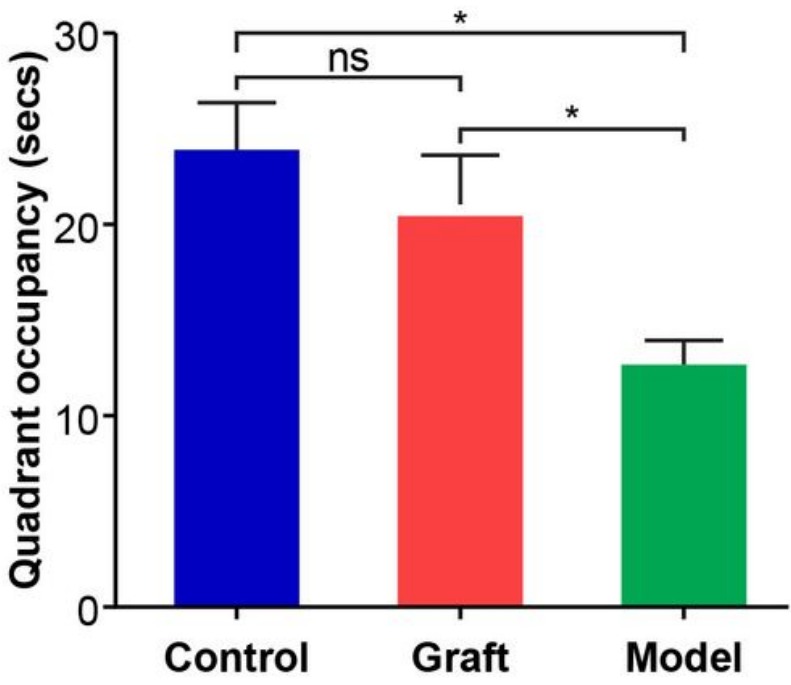

D

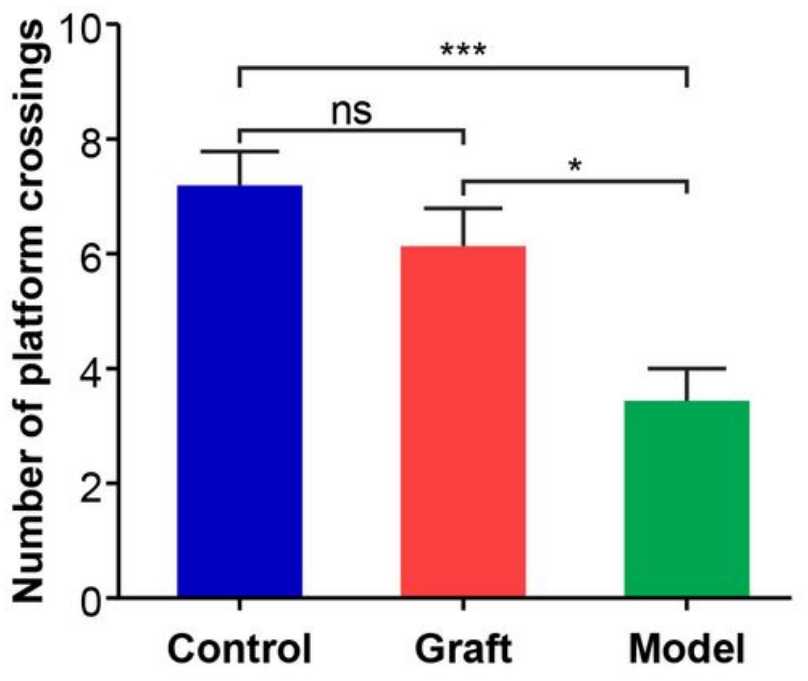

\section{Figure 7}

The effects of transplanted OPCs on behavioral recovery. (A) Representative sample paths from the maze trials. (B) Probe trials were performed $4 \mathrm{~h}$ after the last maze trails on navigation day 5 ; time spent in the target quadrant was monitored. One way ANOVA test, ${ }^{*} \mathrm{P}<0.05$; ns, not significant. (C) Morris water maze task was performed three months later to test the spatial learning ability of control $(n=6)$, model $(n=6)$, and graft $(n=6)$ groups, as shown by the time (escape latency) to find the submerged platform at navigation days 1 to 5. Two-way ANOVA test, ${ }^{*} P<0.05$, ${ }^{* * P}<0.01,{ }^{\star *} \mathrm{P}<0.001$. (D) Probe trials were conducted to monitor the number of crossing platforms in the three groups. One way ANOVA test, ${ }^{*} \mathrm{P}<$ $0.05,{ }^{*} * \star \mathrm{P}<0.001 ; \mathrm{ns}$, not significant. 